moderate sized pictures, the focal length of the lens is less than the distance one would naturally hold the picture at for convenient view, the inevitable result is either that the apparent distances of the picture are greater than the real ones in the proportion of $\underset{\mathrm{F}}{f}$, or that the apparent sizes of the things represented in it are reduced in the proportion $\frac{F}{f}$, or a combination of both these wrong impressions is produced.

Which of these effects or what combination of them is suggested depends much on the nature of the picture itself.

In interiors taken with a wide-angle, short-focussed lens, distances are enormously exaggerated, while in landscapes it is generally the sizes of things which seem diminished.

As a rule, it may be said that objects which do not themselves suggest any scale will be made to look small, while those which do, such as men, houses, \&c., will appear distant.

When $\frac{F}{f}$ is greater than unity, i.e. when the picture is viewed too near, the reverse of the above effects is seen; and as far as the perspective is concerned, the scene is being viewed through a telescope.

The magnifying power of a telescope is the focal length of the object-glass divided by the focal length of the eye-piece, or, in other words, the distance from the lens at which the image is formed divided by the distance from which it is viewed.

If the focal length of the eye-piece is the same as that of the object-glass, there is no magnification, and in the field of the telescope will be seen an exact reproduction of the natural view.

When, however, by shortening the focal length of the eye-piece, magnification is obtained, foreshortening of all the distances in the ratio $\frac{F}{f}$ naturally takes place.

This may be practically illustrated in rather a striking way by looking from a railway bridge along a straight piece of line at an approaching train.

Supposing the train to be travelling at forty miles per hour, if the telescopic power be forty, the apparent rate of approach will be only one mile per hour.

From what has been said, it will be clear that just the same laws apply to photographic pictures (or any pictures in true perspective) as to telescopic images, and that there is only one distance at which they will convey a correct impression to the eye.

This being so, it is evident that any photograph taken with a lens of less than about a foot focal length, must exaggerate all the distances, or make objects in the picture look smaller than they should, and the only remedy for this is to enlarge the picture until the right distance to view it from becomes also the convenient distance.

Even if this be done, however, there is still a tendency to view the picture too far off; for few lenses, except those for portraits embrace an angle so small as to be taken in at a single glance, and people are naturally inclined to stand far enough from a picture to see the whole of it at once.

Still, a proper amount of enlargement offers the best means of making a photograph give a true idea of the scene which it represents; and this is especially true of the small pictures taken by so-called "detective" cameras, having lenses varying from four to six inches in focal length; and it is for this end, and not, in general, to enable more detail to be seen, that the enlarging process is most useful.

Of course, negatives for enlargement must be well enough defined to bear being examined from the focal

NO. I I I 8 , vOI. 43 ] distance of the lens which took them, or less than this (since detail is lost in the enlarging process), and many which would pass muster well enough when held a foot or more off will be found imperfect when looked at from the lesser distance.

In a subsequent article I will, if the Editor permits, enter more fully on the subject of photographic definition and its limits, both as they depend on the nature of the various sensitive films, and on the lenses by which the image is formed.

A. MALLOCK.

\section{EMMILE GAUTIER}

COLONEL GAUTIER was born on April I8, in the year I822, at Geneva, where he made his first studies. When he had concluded his course at the ancient Academy, his tastes and natural talents inclined him to astronomy, the science to which he had been early initiated by his uncle, Alfred Gautier, then Director of the Observatory. In order to perfect himself in his studies, he went to Paris, where, thanks to the recommendations of his uncle, and more especially of Frederic Maurice, a member of the Institute, with whom he was on excelient terms, he entered the Observatory and became the pupil of the celebrated astronomer Leverrier. One of the early recollections that Émile Gautier loved particularly to recall was the time when he worked under the direction of the illustrious savant at the calculations of the perturbations of the planets; he went over again in duplicate all the calculations relative to the perturbations of Uranus, calculations which Leverrier had presented to the Academy of Sciences in November I 845 .

After a stay of about two years in Paris, he returned to Geneva, and published in December 1846 a thesis prompted by the mathematical works in which he had taken part; it was entitled "An Essay on the Theory of the Perturbations of Comets." In the year I847, he sojourned for several months in England, where he made the acquaintance of several eminent English astronomers, among whom were Airy, Challis, Adams, and perhaps others.

On his return he spent some months at Paris, where he made various astronomical researches, and determined among others the elements of the planet Metis. He afterwards returned to Geneva, where, in conjunction with Emile Plantamour, then Director, he worked at the Observatory, especially at magnetic observations.

In 1849 he married Mdlle. V. Sarazin Maurice, granddaughter of Frederic Maurice, already mentioned. He leaves two sons: the elder, Lucien, is at present Professor of Hebrew at Lausanne; the younger, Raoul, in the beginning of 1890 was nominated Professor of Astronomy at the University of Geneva, and succeeded his father at the commencement of the same year as the Director of the Observatory.

In the early part of the year 1850 , pressed by Colonel Aubert and General Dupour, Gautier turned his attention more especially towards a military career, for which he possessed remarkable qualities. His advancement was rapid, and he was considered one of the best officers in the Swiss army. We need not here follow this part of his life, nor note the various administrative functions in connection with which he introduced useful innovations. This subject would lead us far from the limits of this article. We may say, nevertheless, that in his numerous occupations he never lost sight of astronomy, but constantly made himself acquainted with its current progress.

In 1860 he went to Spain to observe the total eclipse of the sun on July 18 at Taragona (Aragon), and gave an account of his observations in the Archives des Sciences Physiques et Naturelles, a publication in which the majority of his works were printed. About this time he had recognized the nature of solar prominences, and defended 
his opinion strenuously against astronomers who still regarded them as appendages of the moon. Afterwards he occupied himself chiefly with the constitution of the sun, and with the study of spots and prominences. $\mathrm{He}$ presented the Observatory with a direct-vision spectroscope by Hoffman, the instrument with which he pursued his researches up to the time when he was confined to his bed in October I 890 .

On the death of Emile Plantamour, Gautier was nominated Director of the Observatory of Geneva, and from the outset displayed great activity in endowing this establishment with new instruments. In meteorology the eye observations have been completed by a self-recording barograph by Hipp, reversing thermometers by Negretti and Zambra, self-recording thermometer and hygrometer by the brothers Richard, and during the last year an anemograph by the same makers. The Meteorological Station of Great Saint-Bernard, which is a sub-station to the Observatory of Geneva, had been likewise supplied with a barograph. In chronometry, an important branch of the Observatory, apart from the usual tests installed by É. Plantamour, Gautier instituted two competitions for the studies of errors of compensation. He has presented the Observatory with an electrical pendulum of extreme accuracy made by Hipp.

If we speak of the man, all astronomers with whom he was acquainted, and they were many, will agree in saying that he was the type of a true gentleman. His cordial welcome, his frankness, his good nature, and his readiness to help, gained for him in succession the love of everyone A day of great happiness for him was that on which the Astronomische Gesellschaft resolved to make Geneva the place of meeting in 1885 ; those who took part in this Congress were able to enjoy his good nature and frank hospitality, and yet a few days before he experienced a cruel grief.

Émile Gautier died from heart disease, by which he was carried suddenly away on the night of February $24-25$.

A. R.

_... _ _ _ _ _ _ _ _ _ _ _ _ _ _ _ _

\section{NOTES}

THE "Flora of British India" has reached the seventeenth part-in other words, the first part of the sixth volume has appeared, and Sir Joseph Hooker may be congratulated on having so nearly accomplished his great task. Since his retirement from the Directorship of Kew Gardens, Sir Joseph has worked single-handed, and several large families yet remain to be done, notably the grasses, which are very numerous, and, in some respects, more difficult than the petaloid monocots, and mainly so because the majority of the species have a much wider area of distribution, thus entailing more literary research. The last published part of "The Flora of British India" is of more than ordinary interest, inasmuch as it contains the conclusion of the descriptive account of the orchids of India. About 1400 species are described; they are referred to upwards of a hundred genera, and they constitute about ten per cent. of the flowering plants of that vast country. This is a larger proportion than that recorded for the rich orchid flora of Mexico and Central America. Among epiphytal, or tree orchids, the beautiful genus Dendrobium contributes upwards of 150 species, and Habenaria among ground orchids numbers 106 species. All lovers of orchids will welcome this masterly synopsis of the Indian species; and all botanists will wish the eminent author health to finish his great work.

THE Camera Club has issued the programme of the fifth annual Photographic Conference, which will be held in the theatre of the Society of Arts on Tuesday and Wednesday, April 7 and 8, under the presidency of Captain Abney. On Tuesday Captain Abney will deliver his presidential address, and NO. I I 18 , VOL. 43 ] papers will be read by Mr. L. Clark, Mr. Joseph Pennell, and the Rev. F. C. Lambert. Major Nott, Mr. C. V. Boys, and Sir H. T. Wood will read papers on Wednesday, and in the evening the members and their friends will dine together at the Criterion Restaurant. All photographers are invited to attend the Conference. The annual exhibition of photographs by members will be on view in the Club-house meeting-room, Charing Cross Road, from ro a.m. to 4 p.m., and it will remain open for about six weeks.

THE Congress of German Geographers was opened in Vienna yesterday. A Gengraphical Exhibition in connection with the Congress was on view at the University. The exhibits consisted chiefly of photographs, maps, and charts.

Throvgr the death of Mr. Henry Groves, on March I, at the age of fifty-six, of paralysis, the English colony at Florence has lost one of its most active scientific members. Mr. Groves had been in business in Florence as a pharmaceutical chemist for about thirty years, and had given the whole of his leisure time to the investigation of the flora, not only of Tuscany, but of nearly the whole of Italy, of which he possessed an exceptional knowledge. His vast stores of information were always at the service of English and other visitors to Florence. His dried collection of Italian plants was probably unrivalled in extent, and has, we are informed, become the property of the Central Botanical Society of Tuscany.

ON Thursday Iast, about midday, two distinct shocks of earthquake were felt at Boscastle, North Cornwall. The first shock was very severe, shaking the windows and furniture in some of the houses. The second shock followed in about two minutes. It was not quite so severe, but was distinctly felt. Some people state that they felt the ground trembling under their feet for several seconds.

DR. H. WILD read a paper before the Imperial Academy of Sciences of St. Petersburg on January 16 last on the use of the electric light for photographic self-registering instruments. $\mathrm{He}$ finds that it is more economical than gas or petroleum, and gives more uniform and sharper curves. Also that it reduces the possibility of loss of continuous registration to a minimum, and completely prevents the disturbance caused by increase of temperature when gas or oil is used.

Mr. C. Callaway has submitted to the Shropshire County Council a report on technical education; and now the Staffordshire County Council has invited him to prepare a similar report on technical instruction in the district occupied by the industries of North Staffordshire.

Mr. R. L. Weighton has been appointed Professor of Engineering and Naval Architecture at the Durham College of Science, Newcastle-upon-Tyne.

Dr. William Somervili.e, having been appointed to the chair of agriculture and forestry recently founded in the Durham College of Science, Newcastle-upon-Tyne, will begin his duties early in the summer. The College has acquired 15 acres of land at Gosforth for the purposes of an experimental station, and it is hoped that smaller stations will be established in other parts of the district. It is the desire of the College that the members of the staff of its agricultural department should assist in the establishment of a system of agricultural education throughout the adjoining counties, partly by a system of "extension lectures" and partly by conducting special classes for teachers.

The Revue Biologique du Nord de la France publishes a paper by $M$. J. de Guerne on the new steam yacht recently built in London for the Prince of Monaco. The Princess Alice is, in fact, a sailing vessel with an engine and screw-propeller to help 